\section{Marco legislativo del suministro de agua en México}

\author{
Jesús Santos Guzmán, ${ }^{1}$ \\ Laura Guerrero Medrano, ${ }^{1}$ \\ Ruth Reyna Caamaño ${ }^{2}$ y \\ Gerardo Mejía Velásquez²
}

Forma de citar: Santos Guzmán J, Guerrero Medrano L, Reyna Caamaño R, Mejía Velásquez G. Marco legislativo del suministro de agua en México. Rev Panam Salud Publica. 2009;26(6):549-52.

Palabras clave: abastecimiento de agua; agua potable; contaminantes ambientales; contaminantes del agua; legislación ambiental; saneamiento; México.

\footnotetext{
1 Escuela de Medicina, Instituto Tecnológico y de Estudios Superiores de Monterrey, Monterrey, México. La correspondencia debe dirigirse a Jesús Santos Guzmán, Centro de Innovación y Transferencia en Salud (CITES), Oficina 305, Av. Morones Prieto No. 3000, CP 64710, Col. Los Doctores. Monterrey, NL, México. Correo electrónico: jsg@itesm.mx

2 Centro de Calidad Ambiental, Instituto Tecnológico y de Estudios Superiores de Monterrey, Monterrey, México.
}

El agua potable es un componente vital para la salud y su acceso un derecho humano fundamental. A nivel mundial se trabaja constantemente para mejorar su disponibilidad, su distribución y, especialmente, su calidad. Si bien la relación más obvia entre calidad del agua y enfermedad se ha dado en los brotes diarreicos provocados por una sanidad deficiente, existen otras asociaciones importantes cuyos efectos no siempre se manifiestan en el corto plazo. Por tal razón, la mayoría de los países cuentan con organismos para la vigilancia del agua, encargados de establecer y monitorear el cumplimiento de los niveles máximos permitidos para varias sustancias.

En general las normas sobre la calidad del agua asumen un medio estable, pero la tendencia hacia la sobrepoblación humana, la creciente necesidad de agua potable (1), la mayor contaminación de los mantos acuíferos y el sobrecalentamiento global sugieren una necesidad urgente de adaptarse al cambio e incrementar el número de parámetros químicos y biológicos de análisis obligatorio, así como la inclusión de nuevas técnicas analíticas con mayor sensibilidad y especificidad. Si se ha de cumplir con este propósito, hará falta implementar nuevos métodos que aumenten la calidad y la seguridad en los diferentes usos potenciales del agua, incluidos el consumo humano y el industrial, así como el uso de agua reciclada. En esta línea podrían recomendarse modificaciones en los patrones de aseo, higiene, limpieza y disposición de desechos de la población general. Si bien algunos de estos patrones han operado por muchos años, la adopción de conceptos como el ahorro de agua o la disposición selectiva de desechos y basura podría facilitar procesos más eficientes de reciclaje de agua.

Considerando la necesidad de adaptarse a las condiciones actuales que influyen en la calidad del agua, en este trabajo se comparan leyes y técnicas mexicanas e internacionales en esta materia, así como la factibilidad de incorporar en la legislatura de México las recomendaciones emitidas por organismos internacionales. En este sentido, se propone revisar el marco legislativo y actualizar aspectos técnicos relacionados con las características microbiológicas, toxicológicas y fisicoquímicas del agua para el desarrollo de indicadores de salud ambiental y su uso en el establecimiento de políticas públicas.

\section{La escasez de agua y la situación del medio ambiente}

Las zonas de menor disponibilidad de recursos hídricos naturales son también precisamente las que soportan mayor presión natural y social. La racionali- 
zación del suministro, junto con la disminución del flujo de aguas superficiales, provoca la concentración de los contaminantes del agua y su paso al aire y al suelo (2). El cambio climático ha causado sequías, inundaciones y estrés ambiental que generan enfermedades emergentes (y reincorporan reemergentes), concentración o dispersión de contaminantes, y aumento en la tasa de mutaciones en microorganismos, favoreciendo la aparición de cepas más agresivas al ser humano.

Todo esto dificulta la disponibilidad y el acceso al agua potable de calidad (3). Más aún, el incremento poblacional y la escasez de agua obligan a utilizar aguas tratadas para diversos usos, lo cual conlleva el riesgo de consumir agua con residuos o contaminantes biológicos y químicos. El aumento en la demanda de agua potable hace que se requieran nuevas fuentes de agua, incluido su reciclaje en todos los niveles, aun el doméstico. Hoy en día preocupa la existencia de fármacos y otros agentes químicos en bajas concentraciones (microtrazas) en los reservorios de agua, con potencial tóxico para el ser humano y otros organismos (4).

\section{La calidad del agua y la salud}

El aumento en la cobertura de agua potable y las medidas sanitarias adoptadas para el tratamiento y la disposición de aguas residuales, así como para proteger los matos freáticos y las fuentes acuíferas superficiales, constituyen uno de los principales logros en materia de prevención de enfermedades relacionadas con la calidad del agua (5). Sin embargo, aunque se ha avanzado mucho en el saneamiento y la protección antimicrobiana, la actividad humana continúa incorporando al agua contaminantes tanto domésticos como industriales. De hecho, la contaminación antropogénica de las aguas no solo incluye elementos biológicos, sino también otros provenientes de fuentes diversas, como la energética, la térmica y la radioactiva, que podrían tener un impacto ecológico importante (cuadro 1), aparte de que pueden provocar daños a la salud tales como enfermedades gastrointestinales agudas e intoxicaciones químicas. Algunos ejemplos de asociaciones entre agentes biológicos contaminantes del agua y enfermedades humanas incluyen Coxsakie virus con diabetes, echovirus con miocarditis, Campylobacter $s p$ con síndrome de Guillain-Barré, Helycobacter sp con cáncer gástrico y Klebsiella $s p$ con artritis reactiva.

\section{Marco regulatorio}

En los Estados Unidos y la Unión Europea se han detectado diferentes cepas de Escherichia coli y ya están desarrollando nuevos métodos para la detección de enterovirus y parásitos. Estados Unidos ha agregado nueve microorganismos como candidatos para ser incluidos en sus normas sobre calidad del agua (cuadro 2). Por su parte, la Organización Mundial de la Salud (OMS) en sus lineamientos ofrece técnicas para la detección de micobacterias, que incluyen 17 especies de bacterias, siete de virus, 10 de protozoarios, dos de helmintos y cianobacterias y ocho indicadores fecales, entre los que se incluyen enterococos, colifagos, enterovirus y Clostridium perfringens $(6,7)$.

\section{Discusión}

Existe una creciente preocupación acerca de la disposición y distribución de agentes químicos y farmacéuticos en los mantos freáticos y eventualmente en el agua potable de las ciudades. La OMS ha propuesto lineamientos para 125 agentes químicos, de los cuales solo en Estados Unidos y en la Unión Europea se aspira a evaluar un poco más de la mitad. Preocupa que algunos de estos agentes químicos pueden actuar como disruptores endocrinológicos o tienen un potencial tóxico o cancerígeno para el humano y la ecología, en cuyo impacto la mayoría de los países deberán poner más atención.

En México y otros países de América Latina la revisión microbiológica del agua incluye la determinación de coliformes, pero sin considerar otras bacterias contaminantes, parásitos y virus entéricos. Estos últimos ya se incluyen en los Estados Unidos y en muchos países de la Comunidad Europea, convirtiéndose en parámetros de calidad y seguridad para la población. En la perspectiva del cambio climático, la abundancia de microorganismos, así como de nuevos agentes infecciosos, dejaría a la revisión microbiológica de coliformes como único rastreo, una opción muy limitada (cuadro 2).

En muchos países la evaluación de contaminantes se realiza por polarimetría, espectrofotometría, gravimetría, titulación, reacciones de óxidoreducción y técnicas de microbiología clásica, lo cual plantea la necesidad de desarrollar técnicas más sensibles y procesos que conlleven la disminución de

CUADRO 1. Lineamientos de la OMS ${ }^{a}$ y parámetros de evaluación obligatoria para el agua potable en varios países y la Unión Europea (en números)

\begin{tabular}{lcccccr}
\hline Parámetro & México & $\begin{array}{c}\text { Estados } \\
\text { Unidos }\end{array}$ & $\begin{array}{c}\text { Unión } \\
\text { Europea }\end{array}$ & España & Colombia & $\begin{array}{c}\text { Lineamientos } \\
\text { de la OMS }\end{array}$ \\
\hline Biológicos & 2 & 7 & 6 & 5 & 2 & 44 \\
Físicos & 3 & 6 & 6 & 4 & 6 & 6 \\
Químicos & 34 & 78 & 64 & 36 & 36 & 125 \\
Radiactivos & 2 & 4 & 2 & 2 & 0 & 2 \\
\hline
\end{tabular}

a OMS = Organización Mundial de la Salud. 
CUADRO 2. Parámetros microbiológicos de detección obligatoria para el agua potable en México, Colombia, Estados Unidos y la Comunidad Europea

\begin{tabular}{lcccc}
\hline \multicolumn{1}{c}{ Parámetro } & México & Colombia & $\begin{array}{c}\text { Estados } \\
\text { Unidos }\end{array}$ & $\begin{array}{c}\text { Comunidad } \\
\text { Europea }\end{array}$ \\
\hline Coliformes fecales & $\mathrm{O}^{\mathrm{a}}$ & 0 & 0 & 0 \\
Coliformes totales & $\mathrm{O}$ & $\mathrm{O}$ & 0 & 0 \\
$\begin{array}{l}\text { Cryptosporidium } \\
\text { Giardia lamblia }\end{array}$ & & & 0 & 0 \\
$\begin{array}{l}\text { Cuenta heterotrófica } \\
\quad \text { en placa }\end{array}$ & & 0 & \\
$\begin{array}{l}\text { Legionella sp } \\
\text { Virus entéricos }\end{array}$ & & 0 & \\
$\begin{array}{l}\text { Clostridium } \\
\text { perfringes }\end{array}$ & & 0 & \\
Streptococcus \\
$\quad$ faecalis & & 0 & 0 \\
\hline a Detección obligatoria. & & & 0 \\
\hline
\end{tabular}

costos mediante el uso de reactivos estandarizados, la automatización y el diseño de métodos prácticos y sencillos (por ejemplo tiras reactivas) (cuadro 3). Muchos de estos eficientes instrumentos ya se utilizan en otros campos en beneficio de la calidad del análisis, aun cuando todavía no han sido incorporados en las normas técnicas de la mayoría de los países. Los retos de estos esfuerzos tecnológicos, los cuales en su mayor parte se encuentran en las fases de desarrollo, son aumentar la sensibilidad y la especificidad, eliminar contaminantes que interfieran con la técnica, aumentar la concentración de patógenos en las muestras, disminuir costos de personal, equipo e infraestructura, determinar qué patógenos son prioritarios y establecer un sistema dinámico de evaluación.

Todo indica que un análisis del costo-beneficio de introducir estos instrumentos seguramente tendrá saldo significativamente favorable si se consideran no solo los costos directos asociados a las enfermedades de transmisión hídrica, sino también los costos indirectos, económicos y sociales, resultantes del impacto ambiental. Las nuevas medidas de detección y cuantificación de algunos contaminantes requieren no solo el uso de las técnicas clásicas, sino también la incorporación de nuevos instrumentos y prácticas que contribuyan a realizar un trabajo más eficiente y completo. Debido a que no existe un parámetro único ni una sola técnica capaces de asegurar inequívocamente la calidad del agua, la tendencia es analizar las características de las fuentes y así implantar la mejor estrategia para asegurar la mejor potabilidad de este elemento esencial para la vida.

CUADRO 3. Métodos en desarrollo para asegurar la calidad del agua, México, 2009

\begin{tabular}{|c|c|c|c|}
\hline Método base & $\begin{array}{l}\text { Método } \\
\text { complementario }\end{array}$ & $\begin{array}{l}\text { Método } \\
\text { complementario }\end{array}$ & Características \\
\hline Medio selectivo & Conteo de colonias & & 24-72 hr. Bacterias, no especifica cepa ni hospedero \\
\hline Filtración & Concentración & Observación microscopio & Parásitos, no específica cepa ni hospedero \\
\hline PCR & $\begin{array}{l}\text { Hibridación } \\
\text { Secuenciación } \\
\text { Cultivo celular }\end{array}$ & & $\begin{array}{l}\text { Identifica cepa, mutación y hospedero } \\
\text { Cuantifica partículas infecciosas }\end{array}$ \\
\hline Pre-Cultivo & PCR/RT-PCR & & $\begin{array}{l}\text { Aumenta la sensibilidad } \\
\text { Limitado a microorganismos cultivables }\end{array}$ \\
\hline PCR Múltiple & & & Varios patógenos simultáneamente \\
\hline Concentración & Enriquecimiento & $\begin{array}{l}\text { PCR/RT-PCR } \\
\text { Cultivo celular }\end{array}$ & $\begin{array}{l}\text { Detecta virus ADN o RNA } \\
\text { Cuantifica partículas virales } \\
\text { Aumenta sensibilidad }\end{array}$ \\
\hline Inmunotinción & & & Identifica el microorganismo \\
\hline Inmunocaptura & $\begin{array}{l}\text { ELISA } \\
\text { PCR/RT-PCR } \\
\text { FISH }\end{array}$ & & $\begin{array}{l}\text { Aumenta la concentración, sensibilidad y especificidad } \\
\text { Elimina interferencias para PCR }\end{array}$ \\
\hline Hidroextracción & PCR/RT-PCR & & $\begin{array}{l}\text { Aumenta la concentración viral, elimina contaminantes } \\
\text { Ideal para virus y fagos }\end{array}$ \\
\hline Citometría de flujo & $\begin{array}{l}\text { Selección celular por } \\
\text { fluorescencia o } \\
\text { anticuerpos específicos }\end{array}$ & & 3 a 5 minutos \\
\hline & & & Aumenta la sensibilidad \\
\hline Medio cromogénico & & & $\begin{array}{l}\text { Aumento sensibilidad detección bacterias } \\
\text { Presencia de fármacos en agua potable }\end{array}$ \\
\hline Cultivo de fagos & & & Cuantifica muestras muy contaminadas \\
\hline
\end{tabular}

Fuentes: referencias 7 a 20.

Abreviaciones: $\mathrm{PCR}$ = reacción en cadena de la polimerasa; $\mathrm{RT}-\mathrm{PCR}=$ transcripción reversa - reacción en cadena de la polimerasa; $A D N=$ ácido desoxirribonucleico; $\mathrm{RNA}=$ ácido ribonucleico; $\mathrm{FISH}$ = hibridación fluorescente in situ. 


\section{SYNOPSIS}

\section{Legislative framework for the water supply in Mexico}

In this study, water sanitation laws and methods (both Mexican and international) are compared, and the feasibility of incorporating recommendations issued by international organizations into Mexican legislation is assessed. When climate, demographic, or industry changes occur, there is an apparent need to broaden the range of substances and organisms being measured and regulated in the water.
This comparative analysis identifies the following challenges: improving equipment sensitivity and specificity; removing contaminants that interfere with the process; increasing pathogen concentration of the sample; reducing manpower, equipment, and infrastructure requirements; identifying priority pathogens; adopting a flexible evaluation system; comparing and evaluating similar efforts carried out by other countries; and lastly, collating local regulations with international ones.

Key words: water supply; potable water; environmental pollutants; water pollutants; legislation, environmental; sanitation; Mexico.

\section{REFERENCIAS}

1. Duarte CM. Cambio global: impacto de la actividad humana sobre el sistema Tierra. Consejo Superior de Investigaciones Científicas (CSIC). Madrid: CSIC 2006.

2. Comisión Nacional del Agua (CNA) de México. Estadísticas del agua en México, 2005. México: CNA; 2005. Pp. 35-7.

3. Lipp EK, Huq A, Colwell RR. Effects of Global Climate on Infectious Disease: the Cholera Model. Clin Microbiol Rev. 2002;15(4):757-70.

4. Reynolds KA. Water Conditioning and Purification Magazine. 2003;45(6).

5. Comisión Nacional del Agua (CNA) de México. Estadísticas del agua en México, 2005. México: CNA; 2005. Pp. 74.

6. World Health Organization (WHO). Organisation for Economic Co-operation and Development. Assessing Microbial Safety of Drinking Water. Geneva: WHO; 2004. Pp 11-8.

7. Comisión Nacional del Agua (CNA) de México. La gestión del agua en México: avances y retos. México: CNA; 2006. Pp. 223-39.

8. Secretaría de Economía de México. Normas técnicas mexicanas. Disponible en: http//www.economia.gob.mx. Acceso el 17 de octubre de 2009.

9. US Environmental Protection Agency. Safe Drinking Water Act. Disponible en: http://www.epa.gov/safewater/regs. html. Acceso el 17 de octubre de 2009.

10. Comunidad Europea. Directiva 2000/ 60/CE del Parlamento Europeo y del Consejo, 23 de octubre de 2000, Marco comunitario de actuación en el ámbito de la política de aguas. Diario Oficial $\mathrm{n}^{\circ}$ L 327 de 22/12/2000. Pp. 1-73.

11. Ministerio de Sanidad y Consumo de España. Ley general de agua de consumo humano para el Estado español. Disponible en: http://sinac.msc.es. Acceso el 17 de octubre de 2009.

12. Ministerio de Desarrollo Económico de Colombia. Reglamento técnico de agua potable y saneamiento básico. Colombia: 2000 .

13. World Health Organization (WHO). Guidelines for Drinking Water Quality. Geneva: WHO; 2005.

14. Ashbolt NJ, Grabow WOK, Snozzi M Indicators of Microbial Water Quality. Water Quality: Guidelines, Standards and Health Assessment of Risk and Risk Management for Water-Related Infectious Disease. WHO Water Series. London: IWA; 2001. Pp. 289-315.

15. Ijzerman MM, Dahking DR, Fout GS. A Method to Remove Environmental Inhibitors Prior to the Detection of Waterborne Enteric Viruses by Reverse-Transcriptase Polymerse Chain Reaction. J Virol Methods. 1997;63:145-53.
16. Jean J, Blais B, Darveau A, Fliss I. Detection of Hepatitis A Virus by Nucleic Acid Secuence-Based Amplification Technique and Comparison With Reverse Transcription-PCR. Appl Environ Microbiol. 2001;67(12):5593-600.

17. Keswick B, Gerba C, DuPont H, Rose JB. Detection of Enteric Viruses in Treated Drinking Water. Appl Environ Microbiol. 1984;47(6):1290-4

18. Queiroz APS, Santos FM, Sassaroli A, Hçarsi CM, Monezi TA, Menhert DU. Electropositive Filter Membrane as an Alternative for the Elimination of PCR Inhibitors from Sewage and Water Samples. Appl Environ Microbiol. 2001;67 (10):4614-8

19. Grabow W. Bacteriophages: Update on Application as Models for Viruses in Water. Water SA. 2001;27(2):251-68.

20. Hegarty JP, Dowd MT, Baker KH. Occurrence of Helicobacter pylori in Surface Water in the United Status. J Appl Microbiol. 1999;87(5):697-701.

Manuscrito recibido el 11 de abril de 2008. Aceptado para publicación, tras revisión, el 28 de octubre de 2008. 